\title{
A longitudinal observation of a patient with normal tension glaucoma
}

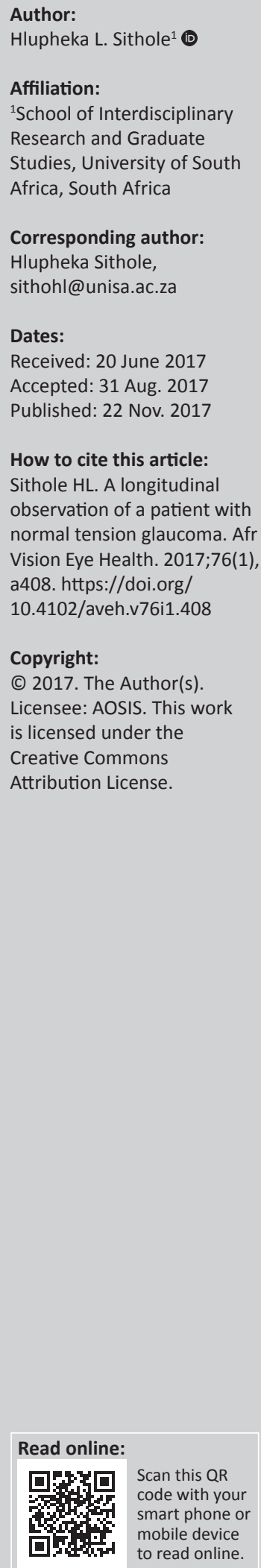

\begin{abstract}
Normal tension glaucoma (NTG) is a disease associated with normal intraocular pressure $(10 \mathrm{mmHg}-21 \mathrm{mmHg})$ that may lead to irreversible blindness if misdiagnosed or left untreated over a period of time. The author observed a patient with NTG over a period of 5 years (from 2013 to 2017). The initial visual field analysis results (2014) showed mild visual field defects because of NTG at the start of the 5-year period. Although the patient was also diagnosed with hydrocephalus, a condition associated with optic nerve head damage, following years of noncompliance to treatment of NTG and follow-up eye examination schedules, the patient's visual field defects were found to have progressed by the year 2017. It is therefore important for optometrists to apply due diligence when examining patients with NTG in order to expedite intervention and prevention of visual impairment and blindness.
\end{abstract}

\section{Introduction}

Glaucoma is a leading cause of irreversible blindness affecting more than 60 million people worldwide. ${ }^{1}$ It accounts for $15 \%$ of blindness in Africa, with the continent having the highest prevalence relative to other regions worldwide. ${ }^{2}$ According to Quigley and Broman, ${ }^{1}$ the number of individuals with bilateral blindness because of glaucoma was expected to increase from 8.4 million in 2010 to 11.1 million by 2020. It is therefore possible that the number of individuals with blindness because of glaucoma is also on the rise. In South Africa, the prevalence of glaucoma in people older than 40 years of age is between $4.5 \%$ and $5.3 \% .^{3}$ Also, approximately $5 \%$ of the black population over 40 years have primary open angle glaucoma (POAG), while the prevalence in the white population is estimated at $1.5 \%{ }^{4,5,6}$ It is reported to be the second leading cause of blindness, after cataract, in South Africa. ${ }^{7}$

In the past, glaucoma was defined as a progressive bilateral neuropathy of the optic nerve fibres because of, in part, ${ }^{8}$ elevated intraocular pressure (IOP)., ${ }^{3,9}$ In recent times, IOP is no longer included in the definition of glaucoma as it is now considered a risk factor for the development of the disease. ${ }^{10}$ As a result, glaucoma is now defined as a group of diseases of the optic nerve which result in a loss of retinal ganglion cells in a characteristic pattern of optic neuropathy which causes characteristic optic nerve head $(\mathrm{ONH})$ cupping and visual field loss. ${ }^{11}$ It is currently recognised as a chronic non-curable condition which is often asymptomatic. Unfortunately, if left untreated, it eventually leads to severe loss of vision and poor quality of life. ${ }^{10,12}$ Treatment, which consists mainly of drugs or surgical procedures to lower IOP, attempts to avoid significant vision loss during the patient's lifetime..$^{12,13}$

Approximately $6.6 \%$ of the normal population in the world may have an IOP greater than $21 \mathrm{mmHg}$ without primary POAG. ${ }^{14}$ The risk factors for the development of POAG include elevated IOP, myopia $>3$ D, old age, male gender, African American, Hispanic and Latino ethnicity, low socioeconomic status, alcohol use and smoking, positive family history, genetic factors, systemic hypertension, type 2 diabetes, cholesterol and coronary heart disease, and vasospastic diseases. ${ }^{10}$ However, individuals with ocular hypertension may have higher baseline IOP, thinner central corneal thickness, older age, higher vertical cup disc ratios $(C D / R)$ and higher pattern standard deviation values with standard automated perimetry. ${ }^{15,16}$ Therefore, IOP alone cannot be used to diagnose or rule out the presence of glaucoma. The outlined risk factors as well as corneal parameters should also be considered.

As indicated above, historically, glaucoma was a disease only associated with increased IOP that if left untreated could lead to blindness. ${ }^{17}$ Contrary to this belief, population-based studies ${ }^{18,19,20}$ have now revealed that some of the patients diagnosed with glaucoma actually had IOPs that were within the normal range. On average, these studies showed that normal tension glaucoma (NTG) occurs in roughly $30 \%-40 \%$ of all patients diagnosed with glaucomatous visual field 
defect. $^{21,22,23}$ Recently a study by Kim et al. ${ }^{24}$ indicated that IOP of less than $21 \mathrm{mmHg}$ accounted for $94.4 \%$ of all glaucomatous cases in their prevalence study among rural Korean adults. This therefore suggests that early diagnosis in these cases may help in eliminating visual impairment and blindness because of NTG. In view of the challenges associated with early diagnosis of NTG, thus leading to timeous intervention, the author presents for educational purposes a case report of a patient seen in his private practice between the years 2013 and 2017.

\section{Case report}

In 2013, a 28-year-old woman presented at the author's private optometric practice for a routine eye examination to obtain spectacles. Following case history, it was established that the patient had never been seen by any eye healthcare professional before and that she had no known systemic diseases. Unaided visual acuity (VA) measurements were normal with both eyes recording 6/6. IOP measurements, using the ICare tonometer, showed $16 \mathrm{mmHg}$ and $14 \mathrm{mmHg}$ for the right and left eyes, respectively. These measurements were not repeated for comparison with any other method for tonometry as rebound tonometer readings are reported to have high correlation with an alternative method such as the Goldmann applanation tonometer. ${ }^{25}$ According to Kouchaki, ${ }^{26}$ more studies are needed to evaluate the effect of different individual corneal properties and their clinical relevance on the IOP measurement. Therefore, for the purpose of this case report, corneal properties and related biomechanical factors were not considered.

Direct ophthalmoscopy revealed $\mathrm{CD} / \mathrm{R}$ of 0.3 and 0.4 for the right and left eyes, respectively. Although the $\mathrm{CD} / \mathrm{R}$ appeared to be within normal limits (usually up to 0.4 ), ${ }^{3}$ the author was concerned with the asymmetrical narrowing of the neuroretinal rim of the ONH in both eyes as shown in Figures 1a and b. The patient was then referred to an ophthalmologist at the Pretoria Eye Institute for further evaluation.

In the following year (2014), the ophthalmologist's report showed that visual field analysis test results revealed mild peripheral visual field loss in both eyes as shown in Figures $2 \mathrm{a}$ and $\mathrm{b}$. Although the diagnosis was not conclusive at this point, the ophthalmologist referred the patient to a neurologist for further evaluation, and the patient was started on Lumigan $0.03 \%$ (Bimatoprost ophthalmic solution) twice a day for a month in both eyes with the aim of reducing the IOP by $30 \%$ from the initial values in each eye. The neurologist then compiled a report in the same year (2014) in which it was indicated that the patient was also suffering from normal pressure hydrocephalus (NPH). The patient was then put on treatment using Acetazolamide (Diamox). The treatment regimen is not known. Although the neurologist had also indicated a possibility of surgery as a way of treatment, follow-up examination after a month of taking the drug showed improvement and as such the neurologist indicated that no surgery will be needed for further treatment of $\mathrm{NPH}$ and subsequently advised the patient to discontinue the use of Acetazolamide.

Unfortunately, the patient did not adhere to follow-up examinations by the ophthalmologist for continuous evaluations between 2014 and 2016. However, the patient was seen by the author for prescription glasses in the year 2015 and no notable changes were observed in the $\mathrm{ONH}$ compared to previous findings as documented in the clinical

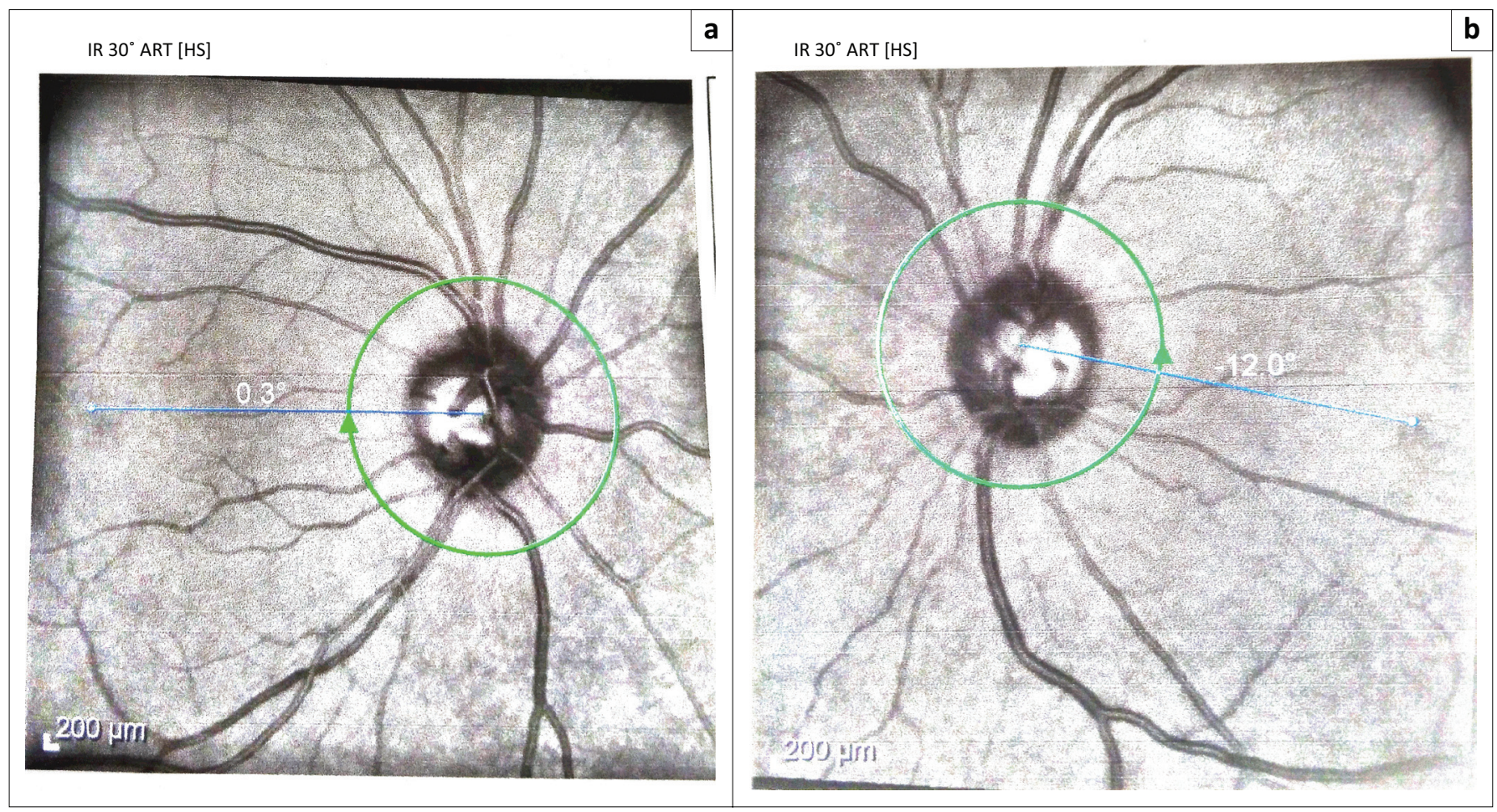

Source: Photos courtesy of Dr Dahya (2014-2017)27

FIGURE 1: Showing the narrowing of the neuroretinal rim of the optic nerve in the (a) right eye and (b) left eye. 


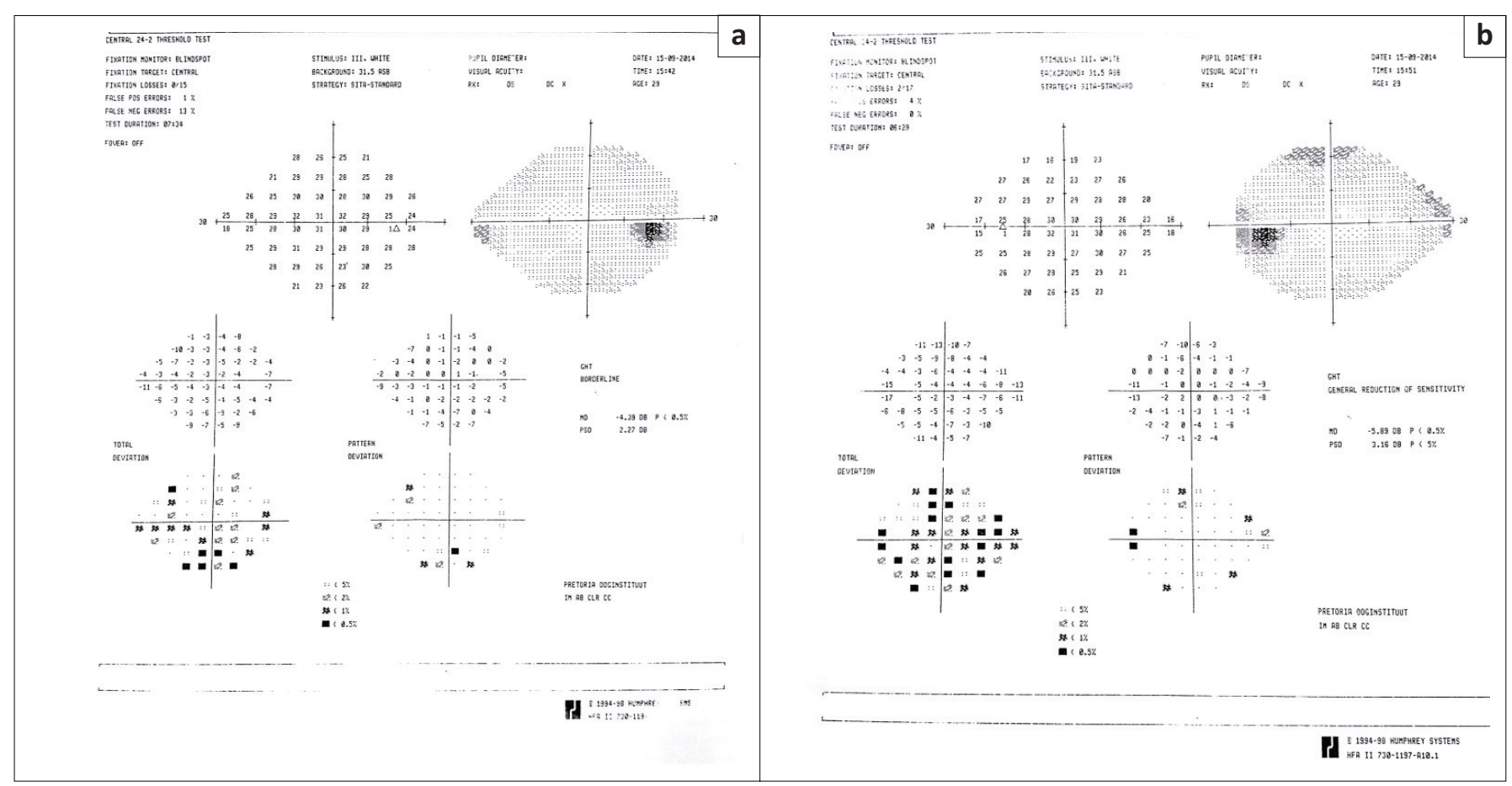

Source: Courtesy of Dr Dahya ${ }^{27}$

FIGURE 2: Showing a baseline field of the (a) right eye and (b) left eye with mild visual field loss in 2014.

record card. At this point, the patient was again advised to continue seeing the ophthalmologist as previously scheduled. However, the patient did not visit the ophthalmologist as recommended.

In the year 2017, the patient presented at the practice again for a routine eye examination and unaided VA in both eyes was still $6 / 6$ and $C D / R$ was 0.4 in both eyes. The neuroretinal rims appeared to be slightly thinner than what was observed in 2013 and 2015. However, the IOPs were within the normal range $(10 \mathrm{mmHg}-21 \mathrm{mmHg})$ at $14 \mathrm{mmHg}$ and $12 \mathrm{mmHg}$ in the right and left eyes, respectively. The patient was then advised to make another appointment with an ophthalmologist for further evaluation.

A report from the ophthalmologist came back with a conclusive diagnosis of NTG this time. Although the optical coherence tomography (OCT) results showed no abnormalities as shown in Figures $3 a$ and $b$, visual field analysis results showed progressive loss of peripheral vision than previously seen in 2014 as shown in Figures 4a and b. The patient was then started on Alphagan $0.15 \%$ (Brimonidine tartrate ophthalmic solution), one drop twice a day indefinitely.

\section{Discussion}

The pathogenesis of NTG remains unclear and it is believed that the interaction of a variety of systemic factors may be involved in the onset and progression of this disease. ${ }^{8}$ One such systemic factor is NPH, which is reportedly a poorly understood entity in the neuroscientific community in relation to how it influences NTG. ${ }^{19,28}$ According to Kovacs, Sparr and $\mathrm{Madu}^{19}$ there is a correlation between glaucoma and NPH. This was also confirmed by Bokhari and Baeesa, ${ }^{28}$ who recommended that during the treatment of $\mathrm{NPH}$, care should be taken to also examine the ONHs for clinical signs of glaucoma because of NTG. It is therefore possible that the narrowing of the neuroretinal rim of the $\mathrm{ONH}$ as seen in this case was associated with the presence of NTG. This further shows the need for retinal examination, possible use of OCT and visual fields analysis on a regular basis to monitor the patients concerned.

Although the role of decreased intracranial pressure in the pathogenesis of POAG has recently been an area of active research, the lack of a scientific method that can consistently halt its progression indicates the inadequacies that exist in understanding the pathophysiology of this disease. ${ }^{28,29}$ Therefore, in diagnosing NTG, all possible risk factors for the progression of this disease should be considered before making a final assertion on the presence of glaucoma and its possible causative factors. This may also explain the reason why the ophthalmologist could not conclusively diagnose this patient with NTG at first consultation despite visual field analysis test results showing mild peripheral visual loss.

Although increased IOPs at diagnosis are generally associated with $\mathrm{ONH}$ changes, ${ }^{18}$ thus indicating the presence of glaucoma and a possibility of impending blindness, the probability of blindness in eyes with NTG should be considered. This phenomenon is reportedly much more common than what was previously thought ${ }^{8}$ and should therefore be taken into consideration when examining eyes with IOPs that are within the normal range but with a presence of noticeable changes in the ONHs. Evidence to support this is seen in the second visual field analysis tests as shown in Figures $4 a$ and $b$, where there is progressive 


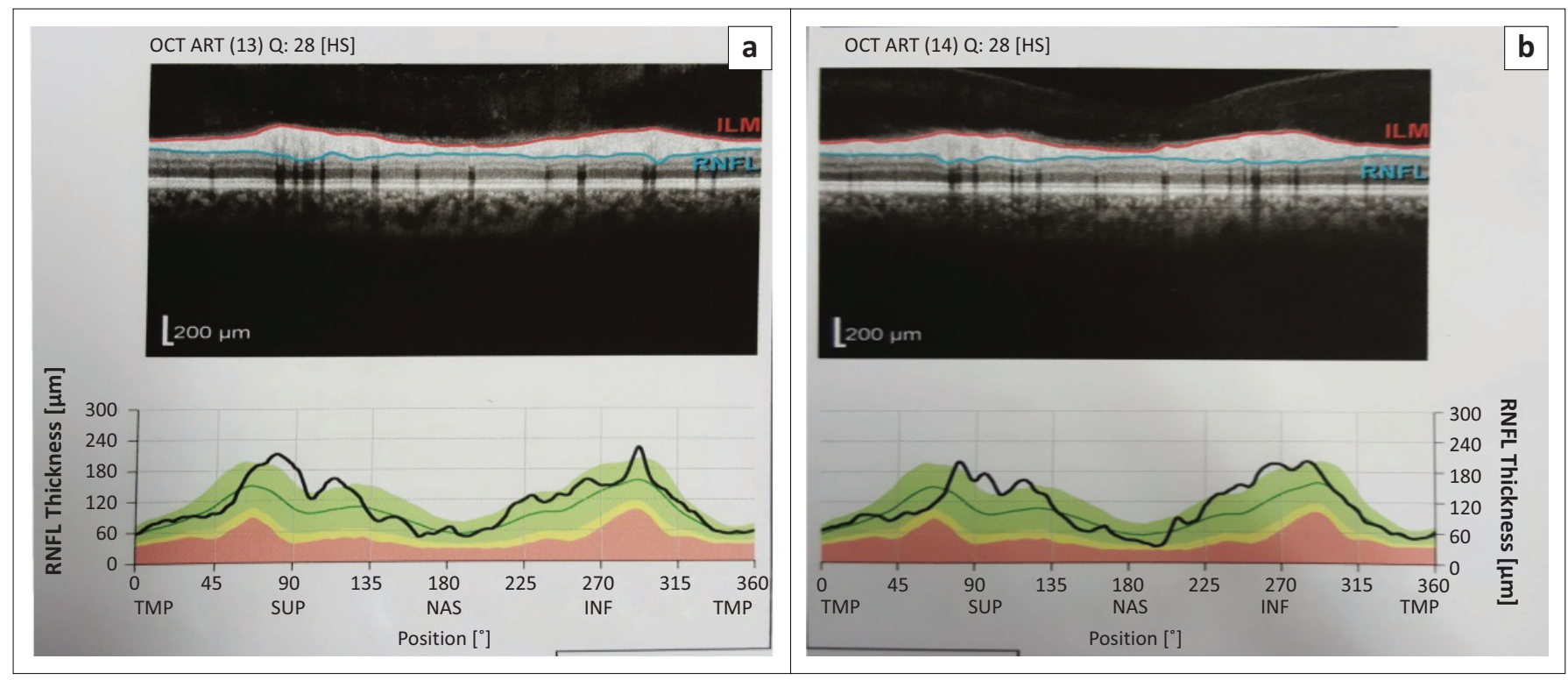

Source: Courtesy of Dr Dahya ${ }^{27}$

FIGURE 3: Optical coherence tomography scan showing the retinal nerve fibre layer thickness of the (a) right eye and (b) left eye with no abnormalities.

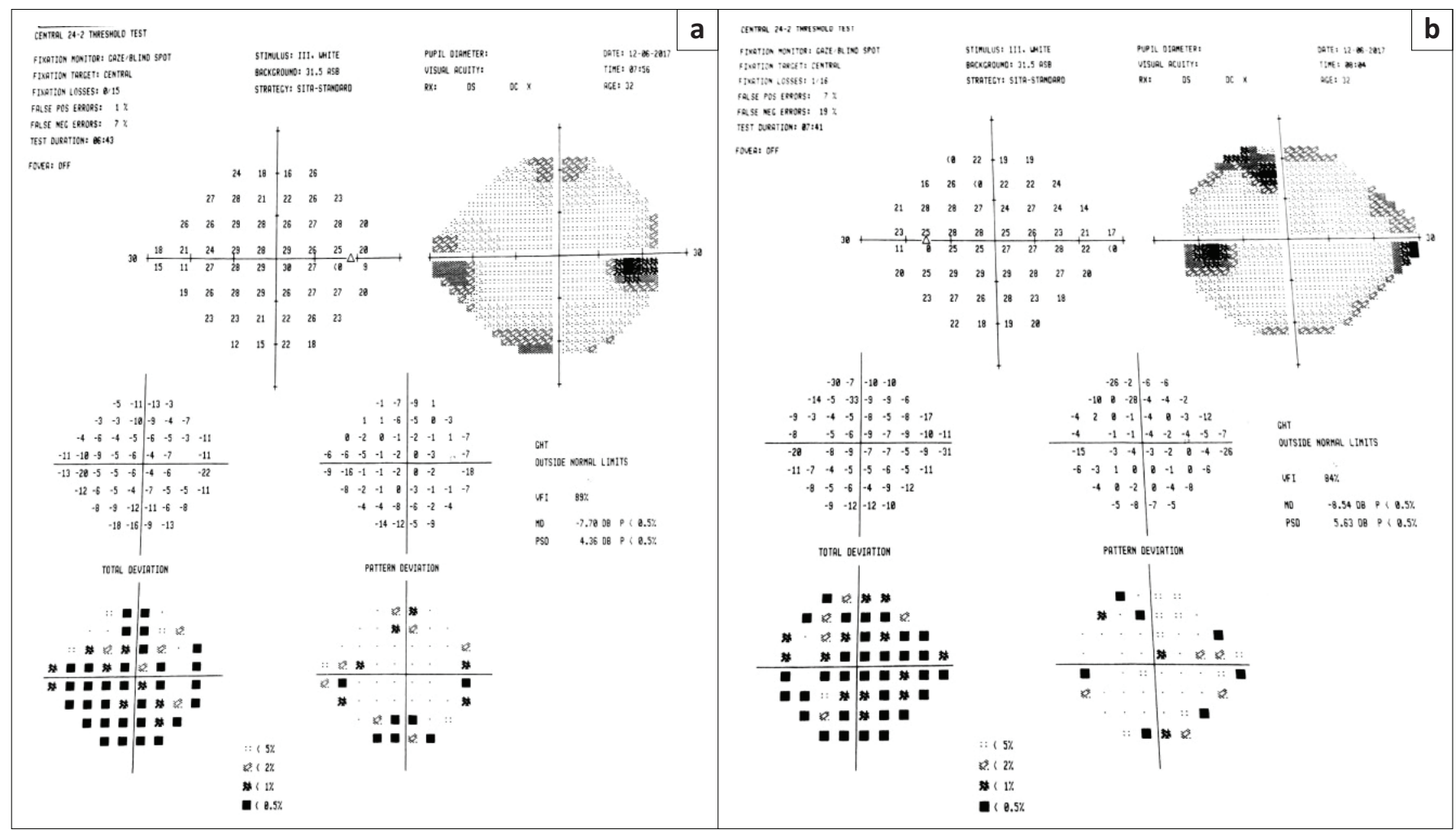

Source: Courtesy of Dr Dahya ${ }^{27}$

FIGURE 4: Showing progressive peripheral visual field loss of the (a) right eye and (b) left eye in 2017 (compare with baseline visual field in Figures 2a and b).

peripheral visual fields loss within 4 years from initial visual field tests.

During the care of patients with NTG, it is important to also consider the clinical differences that may help distinguish between POAG and NTG. Examination of the optic disc in NTG tends to reveal a narrower neuroretinal rim for a given amount of field loss. ${ }^{30}$ This is consistent with the observations reported by the author where the optic discs in both eyes were showing a much narrower neuroretinal rims. Other clinical indicators for NTG may include disc haemorrhages and beta zone peripapillary atrophy. ${ }^{31,32}$

It may also be helpful to introduce the use of an OCT in the diagnosis of glaucoma. It is commonly used as an imaging technology in the evaluation of glaucomatous structural damage. ${ }^{33}$ Its major benefit in the assessment of glaucoma is its increased axial resolution and faster scanning speed that leads to lower susceptibility to eye movement artefacts. ${ }^{33}$ It provides an objective method of quantitatively assessing the damage of the 
$\mathrm{ONH}$ and the nerve fibre layer over time, and hence estimating disease progression. Furthermore, OCT findings also help reassure the patient by showing evidence of current condition or the extent of the loss which can make the patient more inclined to change or accept more aggressive therapy as the need may be. ${ }^{34}$

\section{Conclusion}

In the advent of ocular diagnostics and therapeutic modules currently being undertaken by optometrists in South Africa, understating the nature of NTG is important. Optometrists should note that NTG is a subtype of POAG with distinguishable diagnostic characteristics and management challenges. Furthermore, optometrists should know that although patients with NTG present with IOPs that are within the normal range, the modification of IOP is currently considered the best treatment option through the use of ophthalmic drugs with the aim of reducing IOP by $30 \%{ }^{35}$ The main goal therefore should be to halt the progression of visual field loss and ONHs damage. If this cannot be achieved, surgery may then be considered. It is also important to note that some patients with NTG may also be suffering from NPH. Therefore, when dealing with these patients, proper case history should be obtained in order to refer them appropriately.

\section{Acknowledgements Competing interests}

The author declares that he has no financial or personal relationships that may have inappropriately influenced him in writing this article.

\section{References}

1. Quigley HA, Broman AT. The number of people with glaucoma worldwide in 2010 and 2020. Br J Ophthalmol. 2006;90:262-267. https://doi.org/10.1136/bjo.2005.081224

2. Resnikoff S, Pascolini D, Etya'ale D, et al. Global data on visual impairment in the year 2002. Bull World Health Organ. 2008;82:844-851.

3. Stulting AA, Labuschagne M. Glaucoma: The least the general practitioner should know. Cont Med Edu. 2013;31:1-12.

4. Salmon JF, Mermoud A, Ivey A, et al. The prevalence of primary angle closure glaucoma and open angle glaucoma in Mamre, Western Cape, South Africa. Arch
Ophthalmol. 1993;111(9):1263-1269. https://doi.org/10.1001/archopht.1993. Ophthalmol. 1993

5. Rotchford AP, Johnson GJ. Glaucoma in Zulus: A population-based cross-sectional survey in a rural district of South Africa. Arch Ophthalmol. 2002;120(4):471-478. https://doi.org/10.1001/archopht.120.4.471

6. Rotchford AP, Kirwan JF, Johnson GJ. Exfoliation syndrome in black South Africans. Arch Ophthalmol.2003;121(6):863-870. https://doi.org/10.1001/archopht.121.6.863

7. Department of Health. National Guideline on Prevention of Blindness in South Africa. Directorate: Chronic Diseases, Disabilities and Geriatrics; 2002.

8. Song BJ, Caprioli J. New directions in the treatment of normal tension glaucoma. Ind J Ophthalmol. 2014;62:529-537. https://doi.org/10.4103/0301-4738.133481

9. Grosvenor T. Primary care optometry. Wobum, MA: Butterworth-Heinemann; 2002.

10. Rudnicka AR, Mt-Isa S, Owen CG, et al. Variations in primary open-angle glaucoma prevalence by age, gender, and race: A Bayesian meta-analysis. Invest Ophthalmol prevalence by age, gender, and race: A Bayesian meta-analysis. Invest Opht
Vis Sci. 2006;47(10):4254-4261. https://oi.org/10.1167/iovs.06-0299

11. Coleman AL. Glaucoma. Lancet 1999;354(9192):1803-1810. https://doi.org/ 10.1016/S0140-6736(99)04240-3
12. Heijl A, Bengtsson B, Chauhan BC, et al. A comparison of visual field progression criteria of 3 major glaucoma trials in early manifest glaucoma trial patients. Ophthalmology. 2008;115(9):1557-1565. https://doi.org/10.1016/j.ophtha.2008. 02.005

13. Heijl A, Bengtsson B, Oskarsdottir SE. Prevalence and severity of undetected manifest glaucoma: Results from the early manifest glaucoma trial screening. Ophthalmology. 2013;120(8):1541-1545. https://doi.org/10.1016/j.ophtha.2013.01.043

14. Harper RA, Reeves BC. Glaucoma screening: The importance of combining test data. Optom Vis Sci. 1999;76(8):537-543. https://doi.org/10.1097/00006324199908000-00022

15. Coleman AL, Miglior S. Risk factors for glaucoma onset and progression. Surv Ophthalmol. 2008;53(supp 1):53-510. https://doi.org/10.1016/j.survophthal. 2008.08.006

16. Gordon MO, Beiser JA, Brandt JD, et al. The ocular hypertension treatment study: Baseline factors that predict the onset of primary open-angle glaucoma. Arch Ophthalmol. 2002;120(6):714-720;829-830. https://doi.org/10.1001/archopht. 120.6.714

17. Sawada A, Rivera JA, Takagi D, et al. Progression to legal blindness in patients with normal tension glaucoma: Hospital-based study. Invest Ophthalmol Vis Sci. 2015;56:3635-3641. https://doi.org/10.1167/iovs.14-16093

18. Obstbaum SA, Cioffi GA, Krieglstein GK, et al. Gold standard medical therapy for glaucoma: Defining the criteria indentifying measures for an evidence-based analysis. Clin Ther. 2004;26:2102-2120. https://doi.org/10.1016/j.clintera.2004.12.007

19. Kovacs K, Sparr S, Madu A. Glaucomatous disease in patients with normal pressure hydrocephalus. Ophthalmol Vis Sci. 2014;55:4302.

20. Anderson DR, Drance SM, Schulzer M. The effectiveness of intraocular pressure reduction in the treatment of normal-tension glaucoma. Am J Ophthalmol. 1998;126:498-505. https://doi.org/10.1016/S0002-9394(98)00272-4

21. Sommer A, Tielsch JM, Katz J, et al. Relationship between intraocular pressure and primary open angle glaucoma among white and black Americans. The Baltimore Eye Survey. Arch Ophthalmol. 1991;109:1090-1095. https://doi.org/10.1001/ archopht.1991.01080080050026

22. Mitchell $P$, Smith $W$, Attebo $K$, et al. Prevalence of open-angle glaucoma in Australia. The Blue Mountains Eye Study. Ophthalmology. 1996;103:1661-1669. https://doi.org/10.1016/S0161-6420(96)30449-1

23. Dielemans I, Vingerling JR, Wolfs RC, et al. The prevalence of primary open-angle glaucoma in a population based study in the Netherlands. The Rotterdam Study. Ophthalmology. 1994;101:1851-1855. https://doi.org/10.1016/S0161-6420(94) 31090-6

24. Kim JH, Kang SY, Kim NR, et al. Prevalence and characteristics of glaucoma among Korean adults. Korean J Ophthalmol. 2011;25:110-115. https://doi.org/10.3341/ kjo.2011.25.2.110

25. Sawart S, Haiming D, Jim W. Comparison of intraocular pressure measurements and assessment of intraobserver and interobserver reproducibility with portable Icare rebound tonometer and Goldmann applanation tonometer in glaucoma patients. Glaucoma. 2013;22(4):325-329. https://doi.org/10.1097/IJG.0b013e318237caa2

26. Kouchaki B, Hashemi H, Yekta A, et al. Comparison of current tonometry techniques in measurement of intraocular pressure. I Curr Ophthalmol. 2017;29:92-97. https://doi.org/10.1016/j.joco.2016.08.010

27. Dahya N. Private ophthalmologist. Pretoria Eye Institute; 2014-2017.

28. Bokhari RF, Baeesa SS. Does the treatment of normal pressure hydrocephalus put the retinal ganglion cells at risk? A brief literature review and novel hypothesis. Med Hypotheses. 2013;81:686-689. https://doi.org/10.1016/j. mehy.2013.07.027

29. Berdahl JP, Allingham RR. Intracranial pressure and glaucoma. Curr Opin Ophthalmol. 2010;21:106-111. https://doi.org/10.1097/ICU.0b013e32833651d8

30. Caprioli J, Spaeth GL. Comparison of the optic nerve head in high-and-low-tension glaucoma. Arch Ophthalmol. 1985;103:1145-1149. https://doi.org/10.1001/ archopht.1985.01050080057020

31. Tezel G, Kass MA, Kolker AE, et al. Comparative optic disc analysis in normal pressure glaucoma, primary open-angle glaucoma and ocular hypertension. Ophthalmology. 1996;103:2105-2113. https://doi.org/10.1016/S0161-6420(96)30382-5

32. Ishida K, Yamamoto T, Sugiyama K, et al. Disk hemorrhage is a significantly negative prognostic factor in normal-tension glaucoma. Am J Ophthalmol. 2000;129:707-714. https://doi.org/10.1016/S0002-9394(00)00441-4

33. Bussel II, Wollstein G, Schuman JS. OCT for glaucoma diagnosis, screening and detection of glaucoma progression. Br J Ophthalmol. 2014;98(Suppl II):ii15-ii19. https://doi.org/10.1136/bjophthalmol-2013-304326

34. Dharwadkar S, Nayak BK. Optical coherence tomography in glaucoma-I. J Clin Ophthalmol Res. 2017;5:51-63. https://doi.org/10.4103/2320-3897.195312

35. Collaborative Normal-Tension Glaucoma Study Group. The effectiveness of intraocular pressure reduction in the treatment of Normal-Tension Glaucoma. Am Ophthalmol. 1998;126:498-505. https://doi.org/10.1016/S0002-9394(98)00272-4 